\title{
EFFECT OF THREE-WHEELED VEHICLES ON THE CAPACITY OF A TRAFFIC STREAM
}

\author{
*Sarah H. Abdulamer ${ }^{1}$ \\ Hamid A. Eedan ${ }^{2}$ \\ 1) Highway and Transportation Engineering Department, College of Engineering, Mustansiriyah University, Baghdad, Iraq \\ 2) Civil Engineering Department / College of Engineering / Kufa, University, Najaf, Iraq.
}

\begin{abstract}
Due to the tremendous development of the number and types of vehicles and a large number of traffic congestions, the phenomenon of the spread of threewheeled vehicles, which is characterized by ease of movement, has recently appeared in Iraq because of a small space it occupies for its movement. The increase in their numbers exceeds the number of heavy vehicles in most urban areas in Iraq. Therefore, the current study has been devoted to studying the effect of those vehicles with three tires using a simulation program that has been previously developed and has been calibrated to suit the normal sections where the characteristics of these vehicles were included in terms of speed and length. Different ratios were used, ranging from $(0-15) \%$ for the first lane only. Some general traffic characteristics were examined, such as velocity-flow and flow-density and density-velocity relationship. The results showed that the presence of this type of vehicle has a significant impact on reducing road efficiency and increasing traffic congestion. The study recommends that a particular lane with a width of $2 \mathrm{~m}$ on both directions of the roads be designated for the movement of these vehicles and keep them away from interference in the traffic flow of other cars.
\end{abstract}

Keywords; three-wheeled, simulation, traffic congestion, urban areas.

\section{Introduction}

The knowledge of traffic flow characteristics is an essential input required to plan, analyze, and operate roadway systems [2]. To estimate the traffic volume or capacity of roadway sections under heterogeneous traffic conditions, it is necessary to study the interaction between the moving vehicles over a wide range of roadway and traffic conditions and to understand the traffic congestion problem and the occurrence of bottlenecks, and to find solutions for it, need to study the vehicle-to-vehicle interactions $[3,4]$.

Due to complicated vehicular interactions and maneuvers, it is complex to model the traffic flow off to analytical methods. So, such mixedtraffic flows are commonly modeled through simulation techniques. Research studies on mixed traffic are relatively sparse compared to studies on homogeneous traffic in developed countries [3]. Roads contain types of vehicles, not just passenger cars, like motorcycles, trucks, buses, etc. This versatility leads vehicles not to follow a strict regime of the lane and to occupy any available space on the road. Smaller vehicles, such as two-wheeled vehicles, often use the gaps between vehicles $[5,6]$.

As a result, interactions between vehicles and the resulting maneuvers are more complex in mixed traffic conditions; driving behavior models that describe these interactions are at the core of microscopic traffic simulation systems. Threewheeled vehicles are often seen as a problem, as

\footnotetext{
*Corresponding Author: edma009@uomustansiriyah.edu.iq
} 
a source of unacceptable air pollution with their two-stroke engines, and as a cause of traffic congestion, given their slow speeds and the stops they make to pick up or drop off passengers, or to wait for new customers. Because of the jams and complex traffic conditions and the emergence of increased entry of three-wheeled vehicles significantly on the roads, whose impact on traffic must be studied, it is necessary to know its impact and formulate solutions for the problems emerging. The use of three-wheeled vehicles is widely spreading, especially in India, for more than three decades. The magic of a three-wheeled vehicle is that, like a four-wheeled car and unlike a motorbike, it'll support itself without falling over. There are numerous other advantages: production costs are lower because there is another small wheel for production, saving on maintenance.

\section{Methodology}

The developed simulation model, which has been developed, calibrated, and validated in previous studies $[1,7,8]$, has been used to test different ratios of three-wheeled vehicles $(0,5,10$, and 15$)$ $\%$ of the traffic mix for two-lane section. The main limitation of the developed model could be summarized as:

1. All lane changing activities are according to the standardized behavior, and no violation lane changing is allowed.

2. After completing the first lane changing, there is at least $3 \mathrm{sec}$. The vehicle should be in the new lane before doing another lane changing.

3. No accidents are allowed in the developed model because it was developed according to the safety car-following model (Al-Jameel, 2014 and 2015).

\section{The Developed Simulation Model}

As mentioned above, the developed model has been built and calibrated as described by previous studies such as $[1,7]$. However, some characteristics have been updated, such as lane changing behavior, as indicated in Fig. 1. This figure represents the flow chart of lane-changing behavior at the normal section.

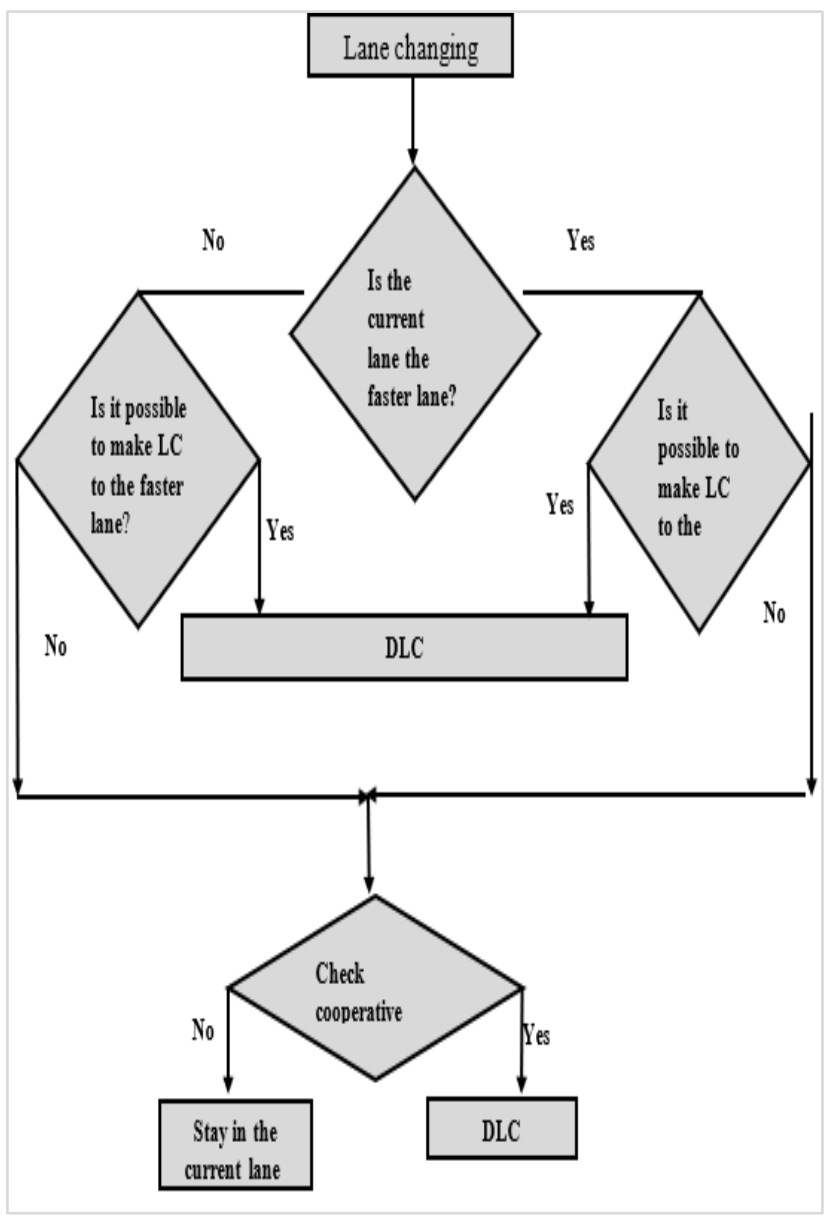

Figure 1. Flow chart of lane changing mechanism

The developed model has been tested for LC under normal conditions, as indicated in Fig. 1. Lane changing behavior is one of the essential calibration factors for developing a simulation model. The behavior obtained by the developed model, as indicated in Fig. 1. Satisfies the observed or field behavior as reported by some researchers such as $[9,12,13]$. 


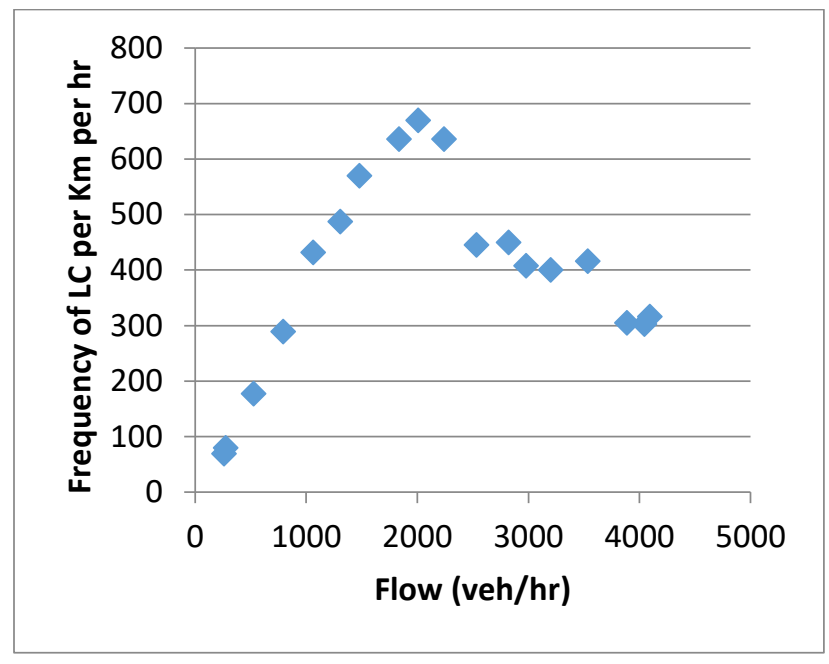

Figure 2. Flow rate for two-lane section (normal section)

\section{The Simulation Model}

In short, the simulation model mainly consists of three sub-models: car-following, gap acceptance, and lane changing. The model was built in the Fortran programming language, and calibration and validation were made as mentioned above. The construction of this model was based on the safety model and on the vehicle-driver characteristics, such as the length of the vehicle, reaction time, and acceleration, which varies according to the position of each vehicle in the system. Other essential characteristics in building models make the model closer to reality. This study added three-wheeled vehicles to the previously developed model, the Al-Jameel model, which contained two types of vehicles, passenger cars, and heavy vehicles, therefore to study three-wheeled vehicle's impact on traffic more clearly.

As a result, Fig. 3and 4 show the screenshot from the developed simulation model for the two-lane section (normal section) with $0 \%$ three-wheeled vehicles when the section has passenger cars and heavy vehicles only. The Fig. 4 explains the twolane section (normal section) with $15 \%$ threewheeled vehicles. The highest percentage of white vehicles is Represent three-wheeled vehicles.

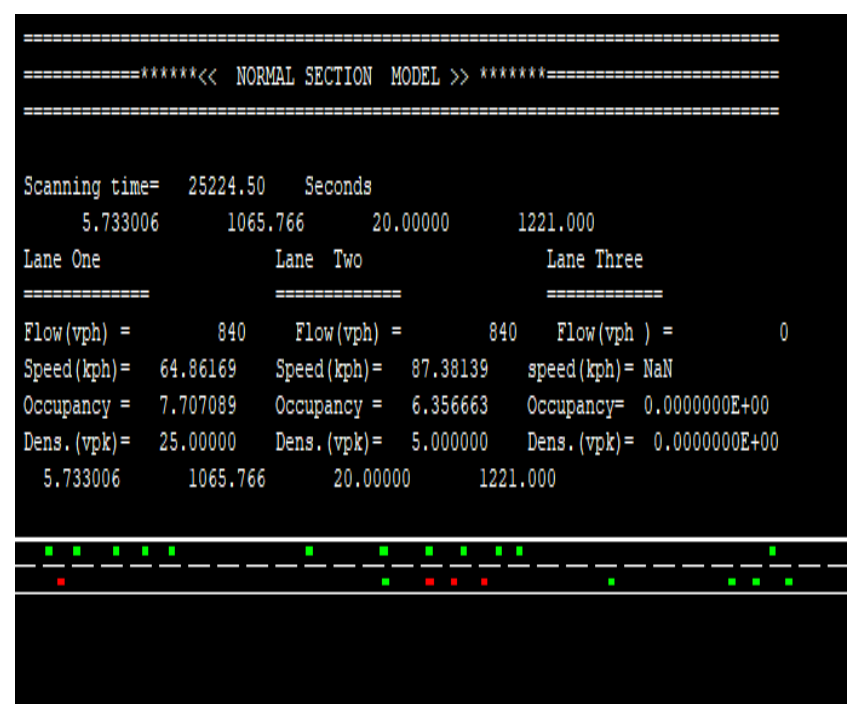

Figure 3. Screenshot from simulation program $0 \%$ threewheeled vehicles

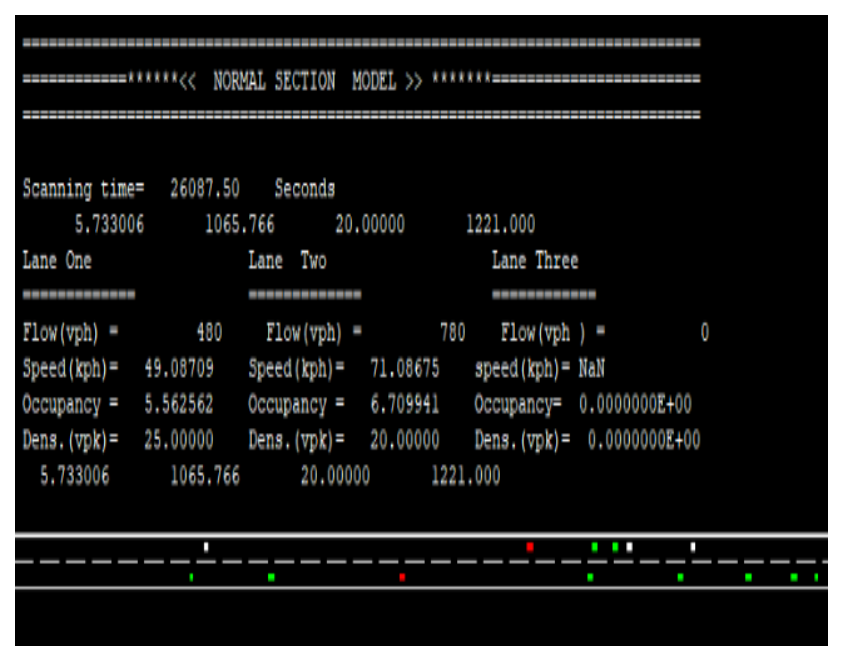

Figure 4. Screenshot from simulation program $15 \%$ three-wheeled vehicles

\section{Testing the Effect of Three-Wheeled Vehicles Using the Developed Simulation Model}

Testing the existence of three-wheeled vehicles within a traffic stream has been implemented into two scenarios: one for a normal section, a twolane section within a rural area, or with high speed. The second one is for a normal section two-lane section within an urban area or with 
moderate speed. For both cases, the exact characteristics of driver and vehicle behaviors have been adopted without any change. In addition, the same set of flow also has been used, as indicated in Table 1.

Table 1. The set of flow for testing traffic behavior

\begin{tabular}{cc}
\hline Period no. (15min) & Traffic flow (veh/hr) \\
\hline 1 & 250 \\
2 & 500 \\
3 & 750 \\
4 & 1000 \\
5 & 1250 \\
6 & 1500 \\
7 & 1750 \\
8 & 2000 \\
9 & 2250 \\
10 & 2500 \\
11 & 2750 \\
12 & 3000 \\
13 & 3250 \\
14 & 3500 \\
15 & 3750 \\
16 & 4000 \\
17 & 4250 \\
18 & 4500 \\
19 & 4750 \\
\hline
\end{tabular}

\subsection{Rural area}

The desired speed for the traffic stream adopted in the developed model could be summarized in Table 2. The primary assumption is that the three-wheeled vehicles are just in the first lane. Both warm-up and cool-off lengths are $1 \mathrm{~km}$ with $300 \mathrm{sec}$ as warm-up time used when started the program; the road is empty from vehicles to avoid unstable conditions during the program's start. The length of three-wheeled vehicles is $3.2 \mathrm{~m}$, and the width of $1.4[10]$.
Table 2. Desired speed for modeled two-lane section (normal section)

\begin{tabular}{cccccc}
\hline Parameters & \multicolumn{2}{c}{ First lane } & \multicolumn{2}{c}{$\begin{array}{c}\text { Second } \\
\text { lane }\end{array}$} \\
& $\begin{array}{c}\text { Pass } \\
\text {.Car }\end{array}$ & $\begin{array}{c}\text { HG } \\
\text { Vs }\end{array}$ & $\begin{array}{c}\text { Three- } \\
\text { wheeled } \\
\text { vehicles }\end{array}$ & $\begin{array}{c}\text { Pass } \\
\text { cars }\end{array}$ & $\begin{array}{c}\text { HG } \\
\text { Vs }\end{array}$ \\
\hline $\begin{array}{c}\text { Mean speed } \\
\text { (kph) }\end{array}$ & 90 & 80 & 45 & 105 & 85 \\
St.D. (kph) & 12.0 & 12.82 & 12.0 & 11.5 & 9.95 \\
\hline
\end{tabular}

\section{A. Lane changing behavior}

After applying different values of three-wheeled vehicles for the normal section with a two-lane section, one could notice the effect of threewheeled cars on the driver behavior. At $5 \%$ of three-wheeled vehicles, the FLC reaches the maximum value comparing with the normal case ( $0 \%$ of three-wheeled vehicles). This could be attributed to the fact that this type of vehicle with a speed of $50 \mathrm{Km} / \mathrm{hr}$ creates a high motivation for other vehicles to make LC avoid losing speed. However, the increasing ratio of three-wheeled vehicles makes the number of LC fewer because the opportunity to get enough gap to conduct the lane changing process is also limited.

On the other hand, for each case, the number of LC as flow increases, the opportunity of LC increases because the reduction of speed for a vehicle makes motivation for the driver to LC to keep his/her speed without a speed reduction. This could be similar for all the cases with all ratios of three-wheeled vehicles, even the typical case (with $0 \%$ of three-wheeled vehicles). 


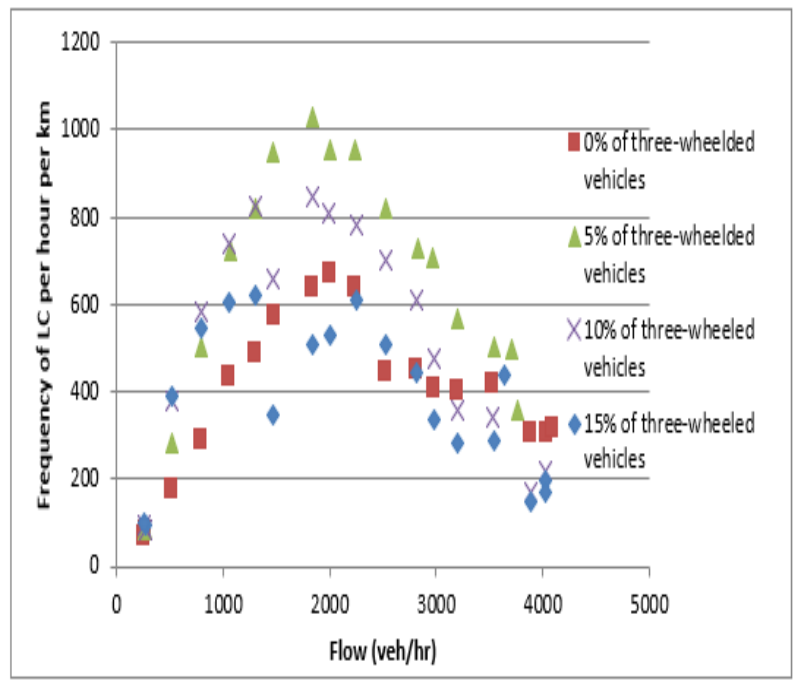

Figure 5. LC frequency with different ratios of threewheeler vehicles

\section{B. Speed-Flow Relationship}

The speed-flow relationship is from the fundamental relation characterizing traffic stream. At $0 \%$ of three-wheeled vehicles, the highest speed and flow recorded simulated values as indicated in Fig. 6. This could be due to the absence of slow vehicles (three-wheeled vehicles). However, for each case, there is a noticeable reduction in speed with increase inflow, according to the Greenshield relationship. Therefore, this indicates that the developed model is approximately close to the field observations. Besides, as the percentage of three-wheeled vehicles increases, both speed, and flow decrease. This could be attributed to increasing the percentage of slow cars that leads to decreasing the speed of the traffic stream, as indicated in Fig. 6.

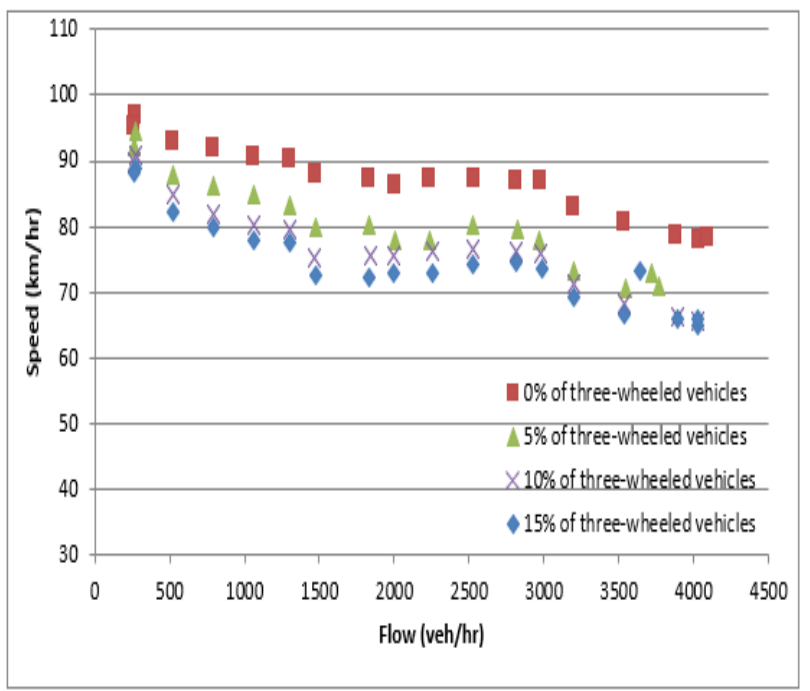

Figure 6. Effect of three-wheeled ratio on the speed-flow relationship

\section{Occupancy-Flow Relationship}

Using the developed simulation model, after installing loop detectors in the developed model, the value of occupancy has been calculated with the flow each $60 \mathrm{sec}$ ( 1 minute) as produced from the real loop detectors. The collected values have been obtained from the simulation model for $0 \%$, $5 \%, 10 \%$, and $15 \%$ of three-wheeled vehicles as indicated in Fig. 7, 8, 9, and 10.

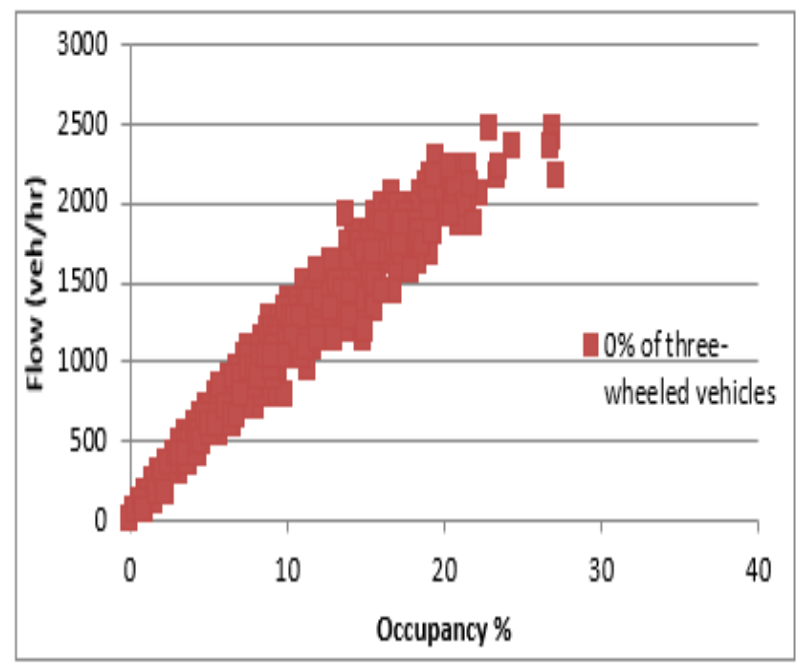

Figure 7. Occupancy-flow relationship at $0 \%$ threewheeled vehicles 


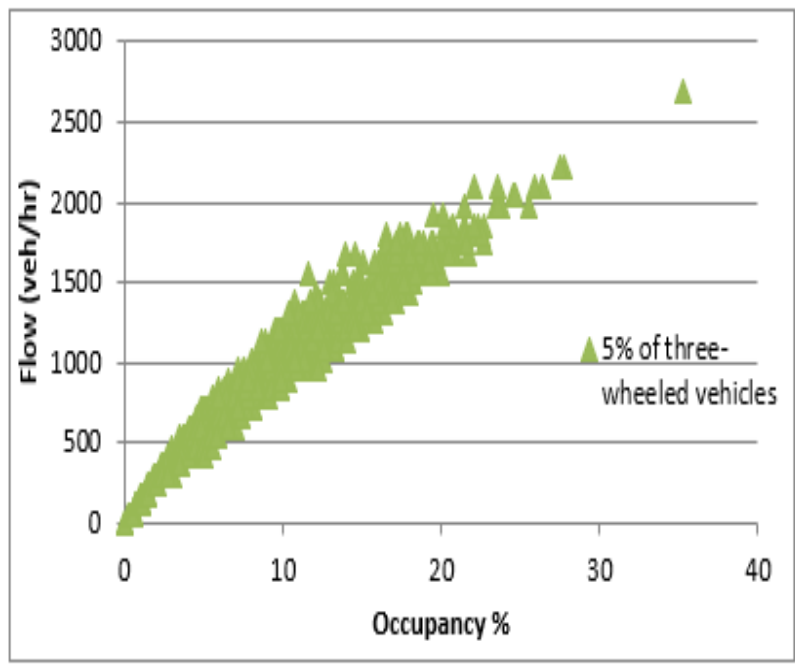

Figure 8. Occupancy-flow relationship at 5\% threewheeled vehicles

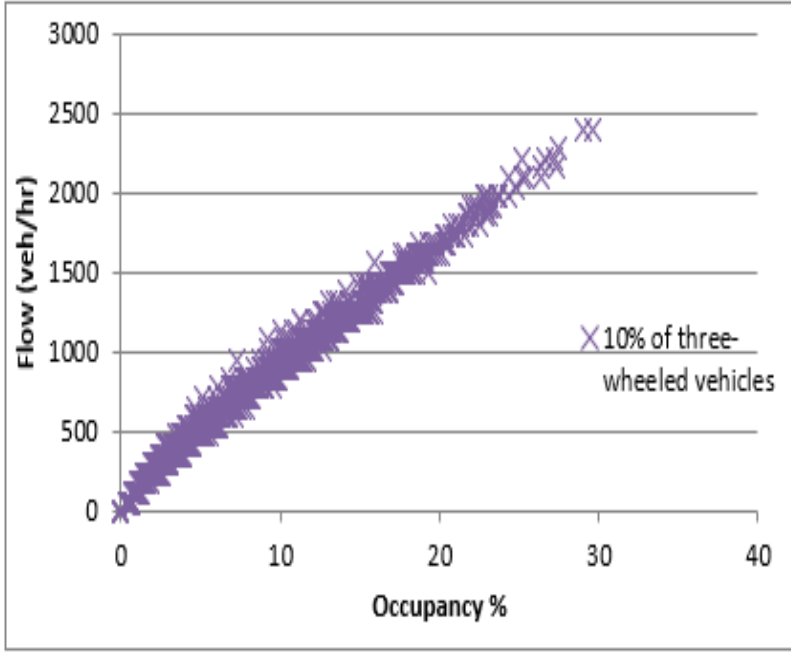

Figure 9. Occupancy-flow relationship at $10 \%$ threewheeled vehicles

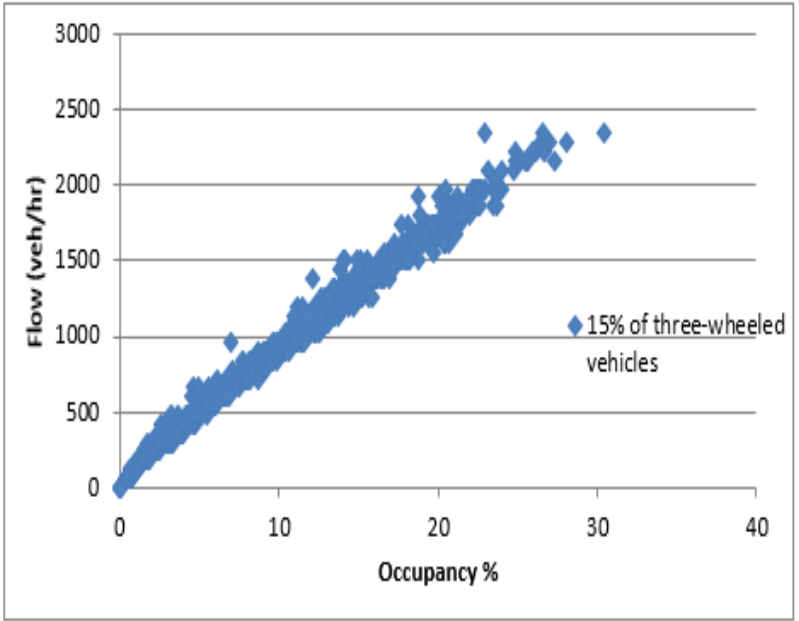

Figure 10. Occupancy-flow relationship at 15\% threewheeled vehicles
When the occupancy is less than $20 \%$, traffic is regarded as not congested; when occupancy lies between 20 and $25 \%$, the traffic is regarded as in the transitional phase, while the traffic is regarded as in the congestion phase occupancy exceeds $25 \%$. At $0 \%$ of three-wheeled vehicles, the occupancy arrived in $27.2 \%$ when traffic flow exceeds 2000(veh/h) that is good but, While the other percentages keep increasing the occupancy with the increase in the percentages threewheeled vehicles, and this leads to more congestion.

\subsection{Urban Roads}

The same characteristics as mentioned for the rural characteristics except for the desired speeds have been adopted, as indicated in Table 3. The main characteristics, as in the rural case, also have been studies such as lane changing behavior, speed-flow relationship, and occupancy-flow relationship.

Table 3. Desired speed for modeled two-lane section (Normal Urban section)

\begin{tabular}{llrrrrr}
\hline Parameters & & & First lane & \multicolumn{2}{r}{$\begin{array}{r}\text { Second } \\
\text { lane }\end{array}$} \\
& $\begin{array}{r}\text { Pass } \\
\text {.Car }\end{array}$ & $\begin{array}{r}\text { HG } \\
\text { Vs }\end{array}$ & $\begin{array}{r}\text { Three- } \\
\text { wheeled } \\
\text { vehicles }\end{array}$ & $\begin{array}{r}\text { Pass } \\
\text { cars }\end{array}$ & $\begin{array}{r}\text { HG } \\
\text { Vs }\end{array}$ \\
\hline $\begin{array}{l}\text { Mean speed } \\
\text { (kph) }\end{array}$ & 80 & 70 & 45 & 95 & 75 \\
St.D. (kph) & 12.0 & 12.82 & 12.0 & 11.5 & 9.95 \\
\hline
\end{tabular}

\section{A. Lane Changing Behavior}

As mentioned in the rural behavior, specific ratios of three-wheeled vehicles have been tested using the developed simulation to investigate its effect on the frequency of LC. Similar behavior as in the rural case with different values as indicated in Fig. 11. 


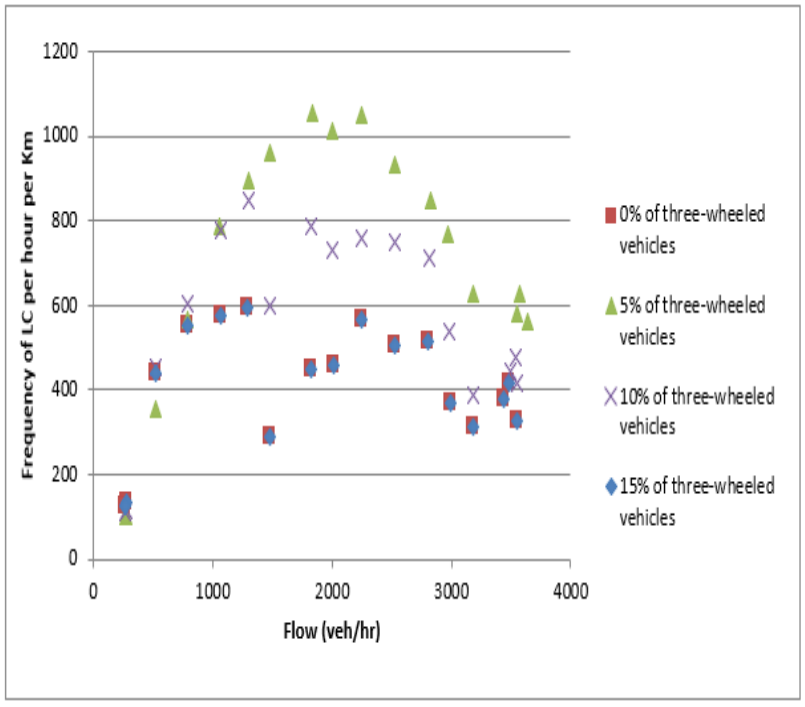

Figure 11. Lane changing behavior with different ratios of three-wheeled vehicles

\section{B. Speed-Flow Relationship}

The speed and flow in urban roads at $5 \%$ of threewheeled vehicles, the highest speed and flow recorded from simulation program as shown in figure Then there was a decrease in the speed with an increase in the flow for each case. On the other hand, when the percentage of threewheeled vehicles increases, speed, and flow decrease.

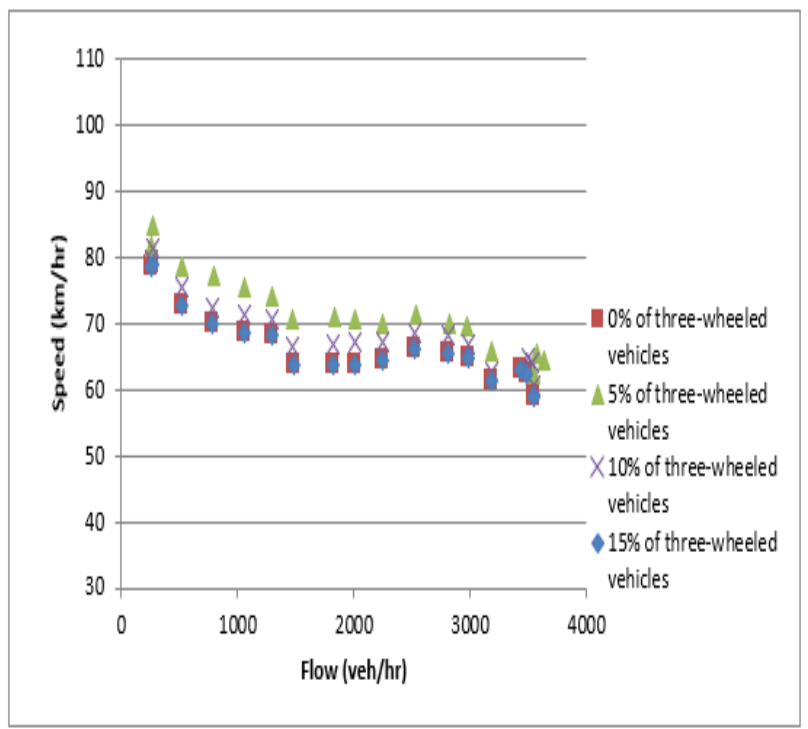

Figure 12. Effect of three-wheeled ratio on the speedflow relationship (urban case)

\section{Occupancy-Flow Relationship}

The collected values have been obtained from the simulation model for $0 \%, 5 \%, 10 \%$, and $15 \%$ of three-wheeled vehicles as indicated in Fig. 13, 14, 15, and 16. Similar behavior as in the rural case with different values the best case is the $0 \%$ and the other, they keep dropping, making more congestion.

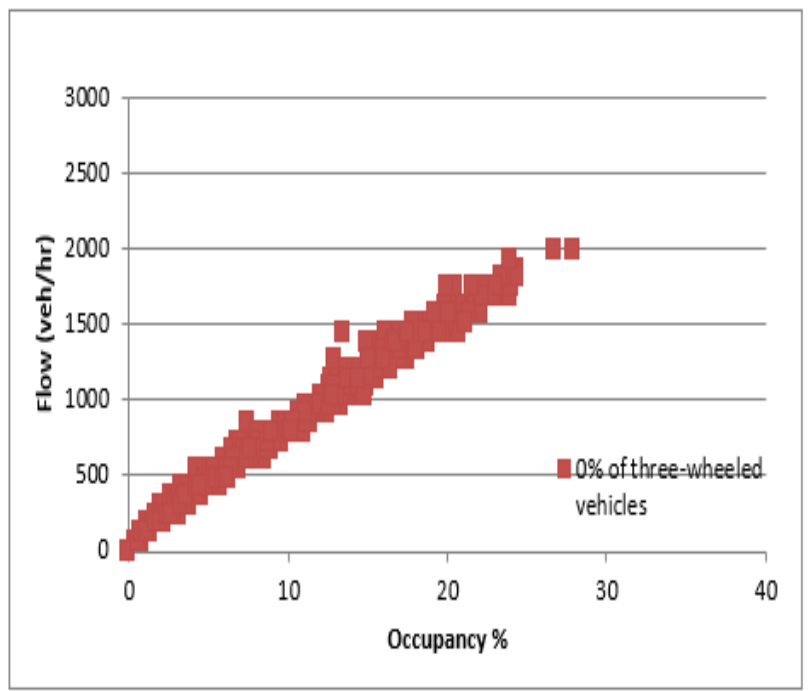

Figure 13. Occupancy-flow relationship at $0 \%$ threewheeled vehicles

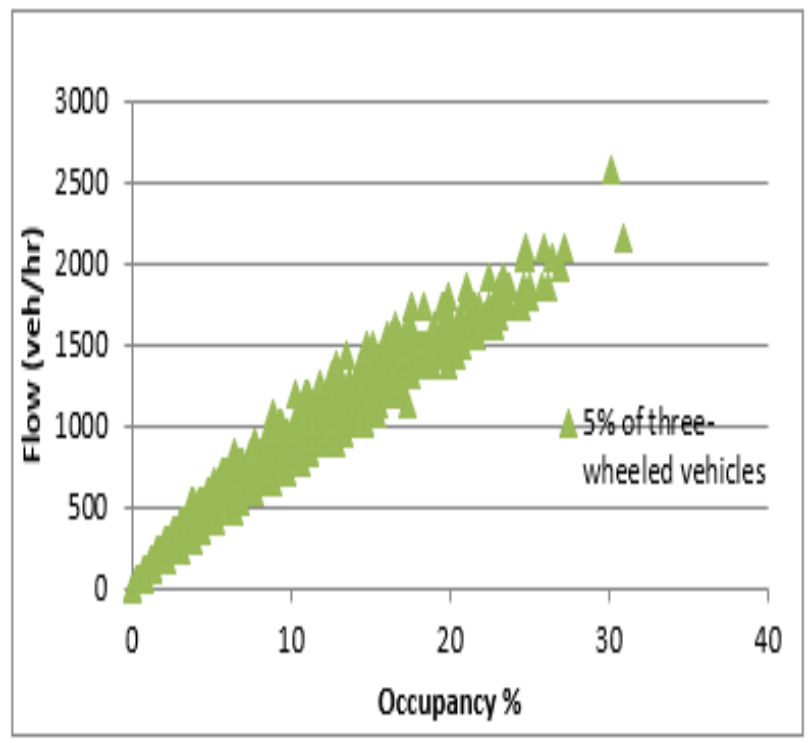

Figure 14. Occupancy-flow relationship at 5\% threewheeled vehicles (urban case) 


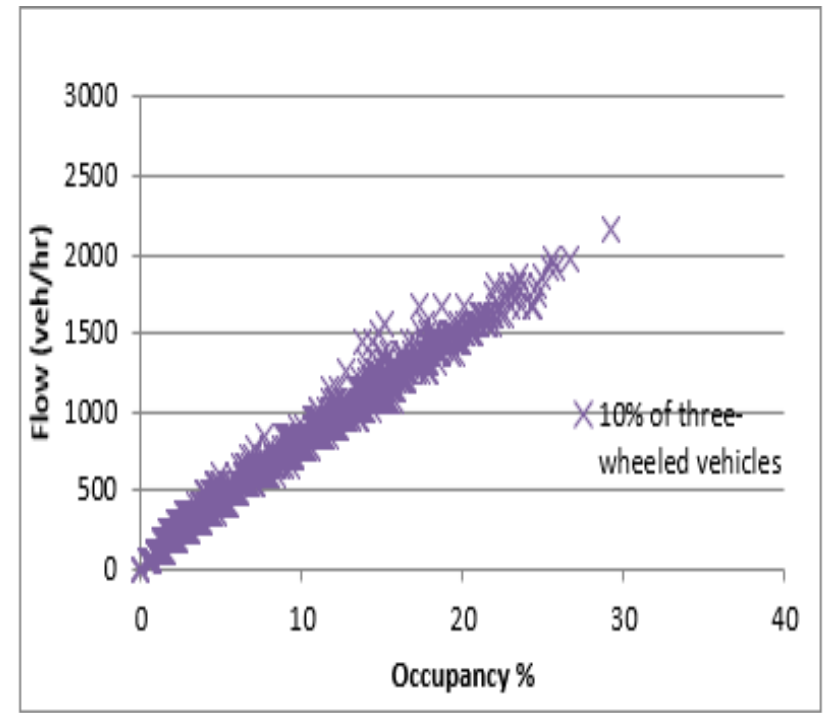

Figure 15. Occupancy-flow relationship at $10 \%$ threewheeled vehicles (urban case)

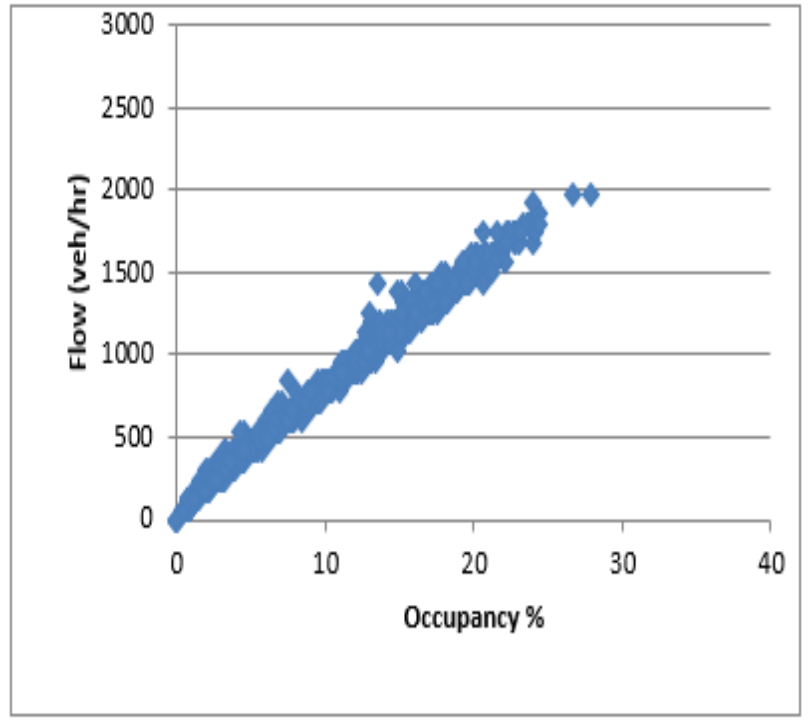

Figure 16. Occupancy-flow relationship at $15 \%$ threewheeled vehicles (urban case)

\section{Conclusions}

The main conclusions of this study are as follows:

1. For the same set of data for both rural and urban environment, the FLC increases at 5\% of three-wheeled vehicles which create noticeable turbulence in the traffic stream due to this type of vehicles. At the same time, $15 \%$ of this type of vehicle leads to the minimum number of LC because of a high restriction on vehicles to change lanes.

2. As for the speed and flow, after analyzing the data, it was found that the traffic condition was better at $0 \%$ of three-wheeled vehicles, but for each case, there is a noticeable reduction in speed with increase inflow. With the percentage increase, the speed and flow began to decrease.

3. In occupancy, the effect of three-wheeled vehicles was also observed, and the higher the proportions, the greater the traffic congestion and its influence on traffic movement.

4. Finally, the effect of three-wheeled vehicles is apparent on the road and the traffic condition, which leads to alternative work. The study recommends allocating a particular lane with a width of $2 \mathrm{~m}$ in both directions of the roads to be designated for the movement of these vehicles and keep them away from interference in the traffic flow of other cars.

\section{Acknowledgement}

Thanks to the highway and transportation department, college of engineering, Mustansiriyah University (www.uomustansiriyah.edu.iq) Baghdad Iraq, to implement the research.

\section{Conflict of interest}

The authors confirm that the publication of this article causes no conflict of interest.
Abbreviations
$\mathrm{LC}=$ Lane Changing
FLC $=$ Frequency of Lane Changing
DLC $=$ Discretionary Lane change

\section{References}

1. Al-Jameel, H. (2014). "Developing a new hybrid safety car-following model". 
Engineering Journal of Kufa, Vol.5 (2), pp.47-60.

2. Arkatkar, S. S. (2018). 'Traffic operations and capacity analysis in india".

3. Asaithambi, G., Kanagaraj, V., Srinivasan, K. K., and Sivanandan, R. (2018). "Study of traffic flow characteristics using different vehicle-following models under mixed traffic conditions". Transportation Letters, 10(2), 92-103.

4. Arasan, V. T., and Shriniwas S. Arkatkar. (2008). "Simulating passenger car unit for vehicles in heterogeneous traffic." Traffic Engineering and Control 49 (11): 436-440.

5. Chakraborty, A. (2014). "Effects of air pollution on public health: the case of vital traffic junctions under kolkata municipal corporation". J Stud Dyn Change 1(3):125-133

6. Arasan, VT, and Koshy, RZ. (2005). "Methodology for modeling highly heterogeneous traffic flow". J Transp Eng ASCE 131(7):544-551

7. Al-Jameel, H. (2015). "developing a simulation model for a three normal section calibrated with iraqi field data". Babylon First International Engineering Conference, 22-23 December. The Iraqi Journal for Mechanical and Materials Engineering, University of Babylon, Iraq.

8. Al-Jameel, H. and Kadhim, A. (2017). "Modeling driver behavior for two and three lane sections in iraqi rural roads". Journal of Al-Qadisiya for Engineering Science, Vol.10 (4).

9. Al-Jameel, H. and Kadhim, A. (2017). "Some traffic characteristics of rural roads in iraq". The third International Conference on Buildings, Construction, and Environmental Engineering (BCEE3) was held in Egypt from 23-25 October 2017.

10. Chandra, S., and Kumar, U. (2003). "Effect of lane width on capacity under mixed traffic conditions in india". Journal of transportation engineering, 129(2), 155160.

11. Ruddy, R. M., and Selbst, S. M. (1990). "Three-wheeled vehicle injuries in children". American Journal of Diseases of Children, 144(1), 71-73.

12. Sultan, B., Brackstone, M., Waterson, B., and Boer, E. R. (2002). "Modeling the dynamic cut-in situation". Transportation research record, 1803(1), 45-51.

13. Yousif, S. (1993). "Effect of lane changing on traffic operation for dual carriageway roads with roadworks". (PhD Thesis), University of Wales, Cardiff 